\title{
Increasing Nature Connection in Children: A Mini Review of Interventions
}

\author{
Alexia Barrable ${ }^{1 *}$ and David Booth ${ }^{2}$ \\ ${ }^{1}$ School of Education and Social Work, University of Dundee, Dundee, United Kingdom, ${ }^{2}$ School of Life Sciences, University \\ of Dundee, Dundee, United Kingdom
}

Half of the world's population live in the urban environment. Lifestyle changes in the 20th century have led to spending more time indoors and less in nature. Due to safety concerns, longer hours in formal education, as well as lack of suitable outdoor environments, children in particular have been found to spend very little time outdoors. We have an opportunity, both timely and unique to have our children (re)connect with nature. Nature connection is a subjective state and trait that encompasses affective, cognitive, and experiential aspects in addition to being positively associated with wellbeing, and strong predictor of pro-environmental attitudes and behaviors. This minireview brings together recent studies that report on interventions to increase nature connection in children. Fourteen studies were identified through electronic searches of Web of Science, Scopus, PsychInfo, ERIC, and Google Scholar. The review aims to offer an overview of the interventions identified, provide a snapshot of the current state of the literature, briefly present themes and trends in the studies identified in relation to nature connection in young people, and propose potential guidelines for future work.

Keywords: nature connection, children, intervention, environmental education, sustainability

\section{INTRODUCTION}

In the 21 st century, numerous voices have been calling for children and adults to (re)connect with nature, both as a wellbeing intervention for humans, but also for environmental sustainability (Miller, 2006; Barker, 2007; Louv, 2008; Capaldi et al., 2015; Díaz et al., 2015). Nature connection, the concept that describes the human-nature relationship, has been described in numerous ways. These related, but not identical constructs have at different times been defined as inclusion of nature in self (Schultz, 2002), nature relatedness (Nisbet et al., 2009), emotional affinity toward nature (Müller et al., 2009), and nature connectedness (Mayer and Frantz, 2004). Despite the subtle differences in these constructs, as well as different instruments to measure them, the underlying construct is very similar and it refers to our perceived and subjective connection to the non- human natural world (Capaldi et al., 2014). A review exploring the similarities and differences between the constructs and measures found that not only do the measures correlated strongly with each other, but that they also shared similar correlations with measures of wellbeing, and ecological beliefs and behaviors (Tam, 2013). For this reason, this paper will include all the constructs mentioned above, and use the umbrella term "nature connection" for ease. 
Several studies have found nature connection is positively associated with wellbeing in adults and children (Mayer and Frantz, 2004; Howell et al., 2011; Nisbet and Zelenski, 2013; Capaldi et al., 2014; Zelenski and Nisbet, 2014; RSPB, 2015). Moreover, feeling close to the natural world has been found to correlate positively with pro-environmental attitudes and ecological behaviors (Mayer and Frantz, 2004; Leary et al., 2008; Nisbet et al., 2009; Frantz and Mayer, 2014). In fact, nature connectedness is a stronger predictor of ecological behaviors in children, than environmental knowledge (Otto and Pensini, 2017). For these reasons, nature connection has been identified as a suitable focus for assessing environmental education (EE) programs (Frantz and Mayer, 2014), as well as a distinct goal for early years' environmental and outdoor education (Otto and Pensini, 2017; Barrable and Arvanitis, 2018; Barrable, 2019a,b).

Childhood is often seen as a time of development for values and beliefs (Wigfield and Eccles, 2002). There is also evidence to suggest that adult nature connection and environmental stewardship may have their roots in childhood (Wells and Lekies, 2006; Andrejewski et al., 2011). Therefore, this current mini-review focuses on activities and interventions that aim to promote nature connection in children. More specifically, the review aims to identify and summarize the key points of interventions that promote a connection to nature in people $<18$ years of age, and provide some guidelines for future research.

\section{MATERIALS AND METHODS}

\section{Inclusion Criteria}

In order to find interventions that promote nature connection the author conducted a literature search adopting the following inclusion criteria. The articles identified had to (i) be published in peer-reviewed journals; (ii) be in the English language; (iii) have used experimental or quasi-experimental design, including randomized controlled trials (RCTs), pre- and post-testing with or without control groups, and included both betweenand within-subjects testing; (iv) have nature connection as a dependent variable; (v) have used a validated instrument for that age group to measure nature connection; and finally (vi) majority of participants were under the age of 18 years.

\section{Data Sources and Search Strategy}

In order to gain a comprehensive coverage of the literature, the following three-fold strategy was used.

(1) Keyword searches were undertaken in the following scientific databases: Web of Science, Scopus, PsychInfo, ERIC, and Google Scholar. The terms used were "nature relatedness," "connection to nature," and "nature connect*, in combination with "intervention," "measure," and "testing."

(2) Specific appropriate journals (such as Journal of Environmental Psychology, Environment and Behavior, Ecopsychology, and others) were targeted and searched using the same terms as above.
(3) Finally, by using Google Scholar the first author manually looked through all publications that cited any of the articles of validation of nature connection measures.

The following information was extracted from each of the publications: age and number of participants, length and type of intervention, design, nature connection measure used, and finally effect size, if reported.

\section{RESULTS}

A total of 3794 articles were initially identified, with 635 remained after duplicates were removed. Those were then screened by title and abstract. Forty-three full articles were read and finally 14 articles were identified as meeting all inclusion criteria.

The ages of participants in the studies ranged from 6 years of age (Bruni et al., 2017) to 19 (Sellmann and Bogner, 2013). All of the studies included pre- and post-intervention measurements, while five also included a control group. The length of activities reported on varied widely, from a short, two-hour field trip reported in Boeve-de Pauw et al. (2019) to programs that lasted several weeks and included regular weekly classes (e.g., Hignett et al., 2018). Environments were also diverse, ranging from the South African bush to the Scottish Highlands, and included urban and wild nature, indoor environments, and coastal areas. Nine of the studies describe activities that were characterized by the authors as EE, while the rest were a mixture of outdoor leisure activities, camps, expeditions, and other educational activities. Several scales were used, which are reported in Table $\mathbf{1 .}$

\section{SUMMARY OF KEY THEMES}

\section{Participant Age as an Influencing Factor}

Some studies looked at the effect of age and reported significant findings. Braun and Dierkes (2017) found that there were significant age-based differences between the samples tested for baseline nature connection, with younger children (10-12) having higher nature connection compared to the older (13-15) group. During analysis, for the 5-day programs 7-9-year olds exhibited the largest shift, while for the 1-day intervention, it was the 17-19-year-old group that showed the greatest positive shift. Finally, looking at follow up after 6 weeks, these two groups (1012 and 17-19) exhibited highest retention of nature connection, with 13-15 showing the biggest decline. Liefländer et al. (2013) reported a marked difference in baseline nature connection levels between younger (9-10-year-old) and older (11-13-yearold) pupils. While both groups showed an increase in levels immediately post intervention, only the younger group (9-10) sustained this at the four-week follow up, indicating perhaps that changes in nature connection in younger children are more likely to be permanent.

\section{Length, Type of Intervention, and Environment}

In studies that compared similar interventions with differing lengths, the longer interventions seemed to have a greater impact 
TABLE 1 | Interventions to increase nature connection as identified in review.

\begin{tabular}{|c|c|c|c|c|c|c|c|c|c|}
\hline Article & $\begin{array}{c}\text { Age of participants } \\
\text { (years) }\end{array}$ & $\begin{array}{l}\text { Length of } \\
\text { intervention }\end{array}$ & Type of intervention & $\begin{array}{l}\text { Type of } \\
\text { environment }\end{array}$ & Design & Control & $\begin{array}{l}\text { Number of } \\
\text { participants }\end{array}$ & Instrument used & $\begin{array}{l}\text { Effect size } \\
\text { (Cohen's } d \text { ) }\end{array}$ \\
\hline Barton et al., 2016 & $11-18$ & $5-11$ days & Wildlife expeditions & Bush/highlands & Pre-post & No & 130 & CNS & $\approx 0.96$ \\
\hline Boeve-de Pauw et al., 2019 & $10-11$ & $2 \mathrm{~h}$ & Field trip (EE) & Heathland & Pre-post & No & 560 & INS & $\approx 0.26$ \\
\hline Braun and Dierkes, 2017 & $7-18$ & 1-day, 5-day & $\begin{array}{l}\text { 1-day field trip } \\
5 \text {-day residential (EE) }\end{array}$ & Rainforest & Pre-post & Yes & 601 & INS & $\approx 0.21$ \\
\hline Bruni et al., 2017 & $6-16$ & $\begin{array}{c}\text { Varied } \\
\text { (30 days - activity } \\
1 \text { to } 30-45 \mathrm{~min} \text { ) }\end{array}$ & $\begin{array}{l}\text { Get to know program } \\
\text { three studies for three } \\
\text { activities } \\
\text { (1) The Creative Arts } \\
\text { Contest, } \\
\text { (2) the Natural Treasure } \\
\text { Adventure, and } \\
\text { (3)Virtual Hikes }\end{array}$ & Urban nature & Pre-post & No & $\begin{array}{l}\text { (1) } 168 \\
\text { (2) } 35 \\
\text { (3) } 50\end{array}$ & $\begin{array}{l}\text { IAT nature } \\
\text { (FlexiTwins) }\end{array}$ & $\approx 0.37$ \\
\hline Bruni et al., 2018 & $6-15$ & Day visit & $\begin{array}{l}\text { Visit to natural history } \\
\text { museum }\end{array}$ & Museum & Pre-post & No & $\begin{array}{c}238 \\
\text { (across two } \\
\text { locations) }\end{array}$ & $\begin{array}{l}\text { IAT nature } \\
\text { (FlexiT wins) }\end{array}$ & $\approx 0.15$ \\
\hline Collado et al., 2013 & Approx. 7-15 & $1-2$ weeks & Summer camps & Mountain camp & Pre-post & $\begin{array}{c}\text { Yes } \\
\text { (urban camp) }\end{array}$ & $\begin{array}{l}397 \\
\text { (four different } \\
\text { camps) }\end{array}$ & EAN & $\approx 0.89$ \\
\hline Ernst and Theimer, 2011 & $8-14$ & $\begin{array}{l}\text { Seven different } \\
\text { programs all which } \\
\text { included sustained } \\
\text { contact with nature }\end{array}$ & EE programs & Urban nature & Pre-post & Yes & Total 385 & $\mathrm{CNI}$ & 0 \\
\hline Hignett et al., 2018 & $13-16$ & 12 weekly lessons & $\begin{array}{l}\text { Surfing and EE program } \\
\text { for "at risk" youth }\end{array}$ & Coast & Pre-post & No & 58 & INS & 0 \\
\hline Kossack and Bogner, 2012 & Approx. 10-16 & 1 day & $\begin{array}{l}\text { Indoor and outdoor EE } \\
\text { program }\end{array}$ & Woodland & $\begin{array}{l}\text { Pre-post and } \\
\text { follow up }\end{array}$ & Yes & $\begin{array}{l}123(\text { and } 116 \\
\text { control) }=239\end{array}$ & INS & $\approx 0.42-0.71$ \\
\hline Liefländer et al., 2013 & $9-13$ & 4-days & EE program on water & Woodland & $\begin{array}{l}\text { Pre-post and } \\
\text { follow up }\end{array}$ & Yes & 264 & INS & $\approx 0.3-0.65$ \\
\hline Mullenbach et al., 2018 & $10-11$ & 4-day & $\begin{array}{l}\text { Residential outdoor EE } \\
\text { program }\end{array}$ & Urban nature & Pre-post & Yes & 163 & Adapted CNS & $\approx 0.11-0.25$ \\
\hline San Jose and Nelson, 2017 & $9-11$ & 4-day & 4-day outdoor program & Woodland & $\begin{array}{l}\text { Pre- and post } \\
\text { and follow up }\end{array}$ & No & 177 & $\mathrm{CNI}$ & $\approx 0.53$ \\
\hline Schneider and Schaal, 2017 & Approx. 10-16 & $\begin{array}{l}\text { 1-day } \\
5 \text {-day }\end{array}$ & $\begin{array}{l}\text { EE program with use of } \\
\text { geogames/treasure hunt } \\
\text { game }\end{array}$ & Woodland & Pre-post & No & 339 & INS (and DCN) & $\approx 0.2$ \\
\hline Sellmann and Bogner, 2013 & $15-19$ & 1-day & EE program & Urban nature & $\begin{array}{l}\text { Pre-post, and } \\
\text { follow up }\end{array}$ & Yes & 114 & INS & $\approx 0.77$ \\
\hline
\end{tabular}


on nature connection (e.g., Sellmann and Bogner, 2013; Braun and Dierkes, 2017). As this trend is observed only within studies, it is impossible to determine whether it is the type, density, or length of the activity that has the effect.

Most of the activities reported on in the studies included in this review were knowledge-rich, with a distinct EE element. Kossack and Bogner (2012) report a negative effect of high information content, while Collado et al. (2013) suggest that enjoyment and play may have a positive effect on nature connection in children. Bruni et al. (2017) found that only the activity in which children engaged artistically with the natural world, such as narrative writing, art work, and photography, created a positive shift in nature connection. Immersive experiences and free outdoor play were seen as a positive feature by Mullenbach et al. (2018) as well as Schneider and Schaal (2017). There was heterogeneity in the types of environments reported, and these environments were idiosyncratic to the location of the study. As such it is difficult to draw any conclusions. A breakdown of different environments can be seen in Table 1, and in relation to effect size of intervention in Figure 1C.

\section{Baseline Connection to Nature and Ceiling Effect}

Overall participants with lower nature connection during pretesting seemed to make the biggest gain in most studies (Braun and Dierkes, 2017; Schneider and Schaal, 2017; Bruni et al., 2018;
Boeve-de Pauw et al., 2019). This could be attributed to a number of potential factors, including a larger observed effect on children who had not previously had contact with natural environments, due to novelty. Additionally, this could be seen to support the Biophila hypothesis (Kellert and Wilson, 1995) that describes an innate tendency of humans to seek connection to nature. Potential methodological reasons may relate to the ceiling effect, explored below. Ceiling effects were reported in several studies (Ernst and Theimer, 2011; Kossack and Bogner, 2012; Barton et al., 2016) which may present a limitation of the instruments used to measure nature connection in young people, with the instrument technically only capable of measuring variation across $50 \%$ of its range of values. It may also be an interesting general property shared across many participants (i.e. an innate, aboveaverage connection to nature).

\section{Analytic Issues and Implications Study Design}

The response of the measure to an intervention may not be linear in nature (Figure 1A). For example, it may be that a hypothetical response to an intervention could rise quickly to a set level (asymptotic); have a threshold value resulting in a sharp increase to a leveling off point (logistic); have a constant rate of increase (exponential); or even in some rare cases the response could be linear. There is some tantalizing evidence that such nonlinear relationships may exist, particularly when contrasting the

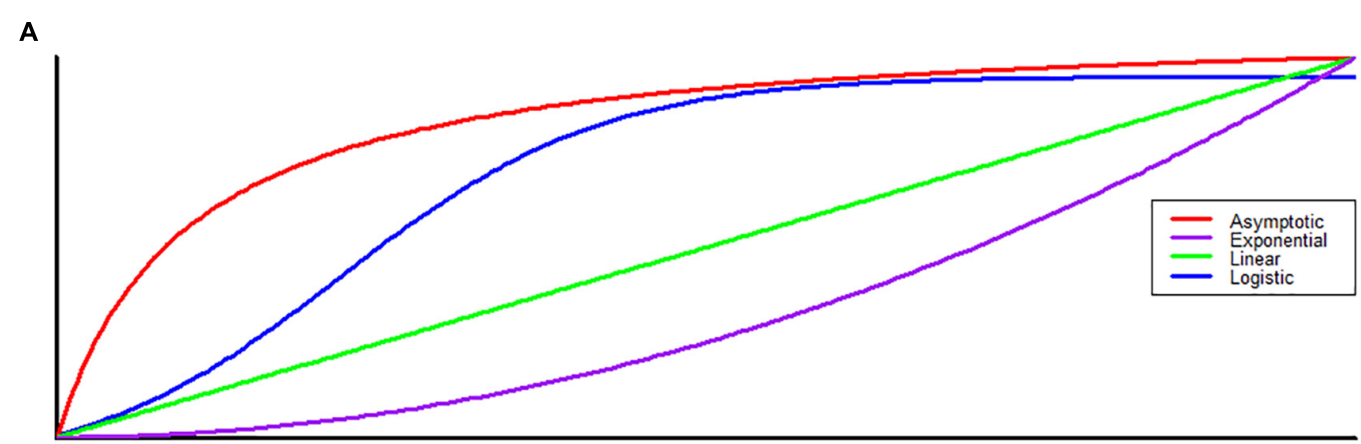

B

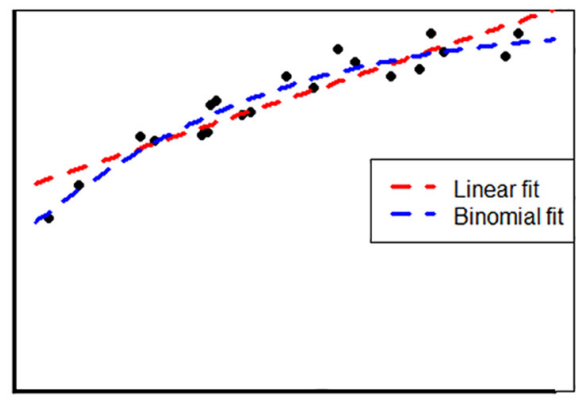

C

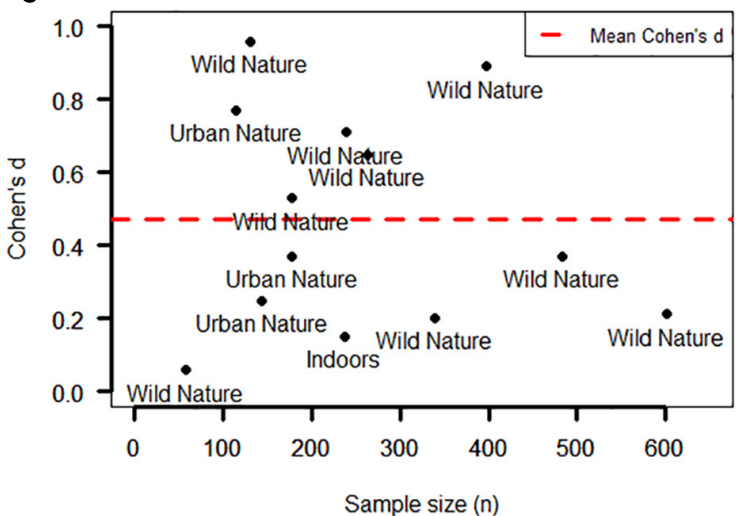

FIGURE 1 | (A) Non-linear responses to an intervention. (B) A poorly fitted linear model and a better fit logistic/binomial model to a simulated curved dataset. (C) Standardized effect with increasing sample size, environment type as a text label. 
effect of interventions in children at either end of the age range, or who start with different baseline nature connectedness scores (Braun and Dierkes, 2017).

Measurements from all but one of the instruments (IAT) have a second property that confounds their analysis using simple statistical tests. Variables from these instruments tend to be bounded (e.g., between one and five) with a great opportunity for variance at the center of a scale, and none at either extreme value. These mean-variance relationships tend not to conform well with linear regression, $t$-testing, and analysis of variance (ANOVA). This has been recognized by statisticians for some time (Nelder and Wedderburn, 1972) resulting in the development of generalized linear models (GLMs). Such models have matured with statistical computing and can explore the effect of independent variables and covariates on a plethora of measured outcomes. Beta, binomial, or quasibinomial GLMs are better suited to handling instruments with bounded outcomes, particularly when a ceiling or floor effect may be present (Figure 1B), and as such study design should take this into account to avoid poorly fitted models (Furr, 2011).

\section{Recommendations for Further Research}

Using CEBM guidelines to evaluate evidence, we noted that most papers would be classified as level 3, i.e., non-randomized comparisons, with a single level 2 study, i.e., a RCT (Braun and Dierkes, 2017) and several level 4 studies, i.e., case series, or pre- and post-studies (Howick et al., 2011). We discuss our evaluation below, ending with recommendations for the field to move forward. There is an aphorism in science of "no controls, no conclusions" (Crawley, 2014, p. 8). Five of the 14 studies incorporated a form of control, with even fewer contrasting their intervention with that of a control set. While pre-post measurements do mitigate this issue somewhat, it is still impossible to discount the possibility of a confounding variable running alongside the intervention, inducing the change (Pearl, 2009). A creative approach would be to incorporate a wait-list control. Recruitment should employ some element of randomization (including cluster randomization) to remove the possibility of systematic confounding variables.

Sample sizes varied over two orders of magnitude $(n=58$ to $n=601)$ and it is conspicuous that the largest studies also reported some of the smallest effects (Figure 1C). Large effects in underpowered experiments are common, due to the conflated false discovery rate (Friston, 2012). Related to this, statistical power $(1-\beta)$ as estimated through a post hoc power analysis (Cohen, 1988) revealed a range of values from the lowest of 0.06 through to the highest of 1.0. This may point toward a likelihood of false negatives in the literature, though it should be noted that half of the studies generally met the conventional threshold of statistical power equaling 0.8 for hypothesis tests. In order to protect against false negatives, we suggest the following as a general guide for minimum sample size, based on effect sizes observed in the most robustly conducted piece of work (Braun and Dierkes, 2017). Assuming an effect size of Cohen's $d \approx 0.2$ a sample size of $n=400$ for unpaired, and $n=200$ for paired (pre-post) comparisons should be able to detect an effect.
We noted the array of statistical approaches employed throughout the literature, from a simple comparison of means (with no standard deviations) through to thorough mixedmodel analysis of co-variance (ANCOVA). Two of the 14 employed omnibus tests with post hoc pairwise comparisons, the remainder conducted multiple pairwise comparisons without some form of correction to minimize the multiple comparisons problem. The problem in its simplest form is that every pairwise comparison carries a type I error rate for $m$ hypotheses $\left(\alpha=1-0.95^{m}\right)$. A single comparison yields a rate of 0.05 , five comparisons is 0.23 , and 10 comparisons is 0.4 . In this set of studies, the most extreme example found conducted 63 pairwise comparisons across a single dataset, yielding an $\alpha$ of 0.96 and meaning that there almost certainly would be false positive observations. This inflation of error can be corrected to mitigate this issue somewhat, through a variety of approaches, the simplest of which being the Bonferroni correction (Dunnett, 1955; Aickin and Gensler, 1996).

To that end we suggest that as a minimum, researchers should clearly report means and standard deviations for each level or group in their study; and for summary statistics a minimum of test statistic, degrees of freedom, $p$-values, and effect sizes. Where the raw data of the experiment require extensive manipulation it is advised to make the dataset publicly available in an anonymized fashion.

General guidelines from the open science framework (OSF) could be used to improve the reliability, reproducibility, and generalizability of studies in this field of environmental and educational psychology (Munafò et al., 2017). We have covered design and analysis above, but other cultural practices could be adopted, such as pre-registration (van't Veer and Giner-Sorolla, 2016), reporting of null results and more transparency in the sharing of data and the analytical workflow.

\section{CONCLUSION}

Throughout this review of studies that evaluate nature connection before and after different interventions, there is a notable absence of evaluations of different type of programs, for example nature kindergartens, forest schools, etc. An exception to this is the study by McCree et al. (2018) which evaluates several aspects of a forest school program in younger children. Part of the difficulty in making such evaluations is the fact that the majority of participants in such programs tend to be younger children (Knight, 2013), while at the same time no self-report instrument to measure nature connection in the early years' age group currently exists (Barrable, 2019b). Finally, the hypothesis of a "critical period" for nature connection could be put to the test in future experimental research.

The majority of studies presented in this review explore EE programs, within a school or other educational context. However, new research suggests that the way to connect to nature is not necessarily through knowledge, but through beauty, emotion, and sustained contact (Lumber et al., 2017). More emphasis could be placed on measuring alternative activities 
that bring children in sustained or condensed contact with nature, such as forest schools, nature kindergartens, adventure activities, and wildlife expeditions.

Further research could include more non-educational interventions that look at the interaction between play or mindfulness, and nature connection (such as ones focused on adults, see Unsworth et al., 2016). Finally, being clear about our intention to facilitate nature connection in children and differentiating between simply providing children with opportunities to be in nature and fostering and nurturing connectedness could further help to identify and highlight which activities are most suited to increasing a child's connection to the natural world.

The review identifies some points of note: One relates to age, and is in accordance with previous literature that highlight the importance of early emotional connection to nature (Wells and Lekies, 2006; Jalongo, 2014). Moreover, earlier studies have found that length of time, as well as time spent in nature during childhood are the two most significant predictors of emotional affinity toward the natural world (Kals et al., 1999; Andrejewski et al., 2011). This review reinforces this and further highlights the fact that changes in nature connection in younger children may be more resistant to change over time.

\section{REFERENCES}

Aickin, M., and Gensler, H. (1996). Adjusting for multiple testing when reporting research results: the Bonferroni vs Holm methods. Am. J. Public Health 86, 726-728. doi: 10.2105/ajph.86.5.726

Andrejewski, R., Mowen, A. J., and Kerstetter, D. L. (2011). An Examination of Children's Outdoor Time, Nature Connection, and Environmental Stewardship. Available online at: https://scholarworks.umass.edu/cgi/viewcontent.cgi? article $=1001 \&$ context $=$ nerr $($ accessed March 11, 2019).

Barker, S. (2007). Reconnecting with nature. J. Biol. Educ. 41, 147-149. doi: 10. 1080/00219266.2007.9656089

Barrable, A. (2019a). Refocusing environmental education in the early years: a brief introduction to a pedagogy for connection. Educ. Sci. 9:61. doi: 10.3390/ educsci9010061

Barrable, A. (2019b). The case for nature connectedness as a distinct goal of early childhood education. Int. J. Early Child. Environ. Educ. 6, 59-70.

Barrable, A., and Arvanitis, A. (2018). Flourishing in the forest: looking at Forest School through a self- determination theory lens. J. Outdoor Environ. Educ. 22, 39-55. doi: 10.1007/s42322-018-0018-5

*Barton, J., Bragg, R., Pretty, J., Roberts, J., and Wood, C. (2016). The wilderness expedition: an effective life course intervention to improve young people's wellbeing and connectedness to nature. J. Exp. Educ. 39, 59-72. doi: 10.1177/ 1053825915626933

*Boeve-de Pauw, J., Van Hoof, J., and Van Petegem, P. (2019). Effective field trips in nature: the interplay between novelty and learning. J. Biol. Educ. 53, 21-33. doi: 10.1080/00219266.2017.1418760

*Braun, T., and Dierkes, P. (2017). Connecting students to nature-how intensity of nature experience and student age influence the success of outdoor education programs. Environ. Educ. Res. 23, 937-949. doi: 10.1080/13504622.2016. 1214866

*Bruni, C. M., Ballew, M. T., Winter, P. L., and Omoto, A. M. (2018). Natural history museums may enhance youth's implicit connectedness with nature. Ecopsychology 10, 280-288. doi: 10.1089/eco.2018.0025

*Bruni, C. M., Winter, P. L., Schultz, P. W., Omoto, A. M., and Tabanico, J. J. (2017). Getting to know nature: evaluating the effects of the get to know program on children's connectedness with nature. Environ. Educ. Res. 23, 43-62. doi: $10.1080 / 13504622.2015 .1074659$

${ }^{*}$ References that have an asterisk are studies included in the review.
The second point relates to the way we measure nature connection and possible limitations of our current instruments. This includes limitations in the age-range of validated measures, no self-report measures currently exist for children under 8 years of age (Barrable, 2019a), as well as the fact that current measures may impose an artificial ceiling effect that prevents us from measuring changes in highly connected individuals.

Finally, the last point raised in this review relates to the design, recruitment, and consistency of reporting, which makes the quality of the evidence weaker than it could be, given the amount of effort and relative ease with which they could be rectified. To that effect, we propose the above guidelines for future research and reporting in this field.

\section{AUTHOR CONTRIBUTIONS}

$\mathrm{AB}$ conceived, designed, and undertook the review. $\mathrm{DB}$ reviewed the search results, assisted in compiling the table, and undertook the statistical analysis, reporting, and visualizations. $\mathrm{AB}$ drafted the final report. $\mathrm{AB}$ and $\mathrm{DB}$ contributed and approved the final version of the manuscript.

Capaldi, C. A., Dopko, R. L., and Zelenski, J. M. (2014). The relationship between nature connectedness and happiness: a meta-analysis. Front. Psychol. 5:976. doi: 10.3389/fpsyg.2014.00976

Capaldi, C. A., Passmore, H. A., Nisbet, E. K., Zelenski, J. M., and Dopko, R. L. (2015). Flourishing in nature: a review of the benefits of connecting with nature and its application as a wellbeing intervention. Int. J. Wellbeing 5, 1-16. doi: 10.5502/ijw.v5i4.1

Cohen, J. (1988). Statistical Power Analysis for the Behavioral Sciences, 2nd Edn. Hillsdale, NJ: Lawrence Erlbaum Associates.

*Collado, S., Staats, H., and Corraliza, J. A. (2013). Experiencing nature in children's summer camps: affective, cognitive and behavioural consequences. J. Environ. Psychol. 33, 37-44. doi: 10.1016/j.jenvp.2012.08.002

Crawley, M. J. (2014). Statistics: An Introduction Using R, 2nd Edn. Chichester: Wiley \& Sons.

Díaz, S., Demissew, S., Carabias, J., Joly, C., Lonsdale, M., Ash, N., et al. (2015). The IPBES conceptual framework-connecting nature and people. Curr. Opin. Environ. Sustain. 14, 1-16. doi: 10.1371/journal.pbio.10 02040

Dunnett, C. W. (1955). A multiple comparison procedure for comparing several treatments with a control. J. Am. Stat. Assoc. 50, 1096-1121. doi: 10.1080/ 01621459.1955.10501294

Ernst, J., and Theimer, S. (2011). Evaluating the effects of environmental education programming on connectedness to nature. Environ. Educ. Res. 17, 577-598. doi: $10.1080 / 13504622.2011 .565119$

Frantz, C. M., and Mayer, F. S. (2014). The importance of connection to nature in assessing environmental education programs. Stud. Educ. Eval. 41, 85-89. doi: 10.1016/j.stueduc.2013.10.001

Friston, K. (2012). Ten ironic rules for non-statistical reviewers. NeuroImage 61, 1300-1310. doi: 10.1016/j.neuroimage.2012.04.018

Furr, M. (2011). Scale Construction and Psychometrics for Social and Personality Psychology. Thousand Oaks, CA: SAGE Publications Ltd.

*Hignett, A., White, M. P., Pahl, S., Jenkin, R., and Froy, M. L. (2018). Evaluation of a surfing programme designed to increase personal well-being and connectedness to the natural environment among 'at risk'young people. J. Adventure Educ. Outdoor Learn. 18, 53-69. doi: 10.1080/14729679.2017. 1326829

Howell, A. J., Dopko, R. L., Passmore, H. A., and Buro, K. (2011). Nature connectedness: associations with well-being and mindfulness. Pers. Individ. Dif. 51, 166-171. doi: 10.1016/j.paid.2011.03.037 
Howick, J., Phillips, B., Ball, C., Sackett, D., Badenoch, D., Straus, S., et al. (2011). Oxford Centre for Evidence-Based Medicine-Levels of Evidence (March 2009). Centre for Evidence Based Medicine. Available online at: https://www.cebm.net/ wp-content/uploads/2014/06/CEBM-Levels- of-Evidence-2.1.pdf (accessed January, 2020).

Jalongo, M. R. (2014). Teaching Compassion: Humane Education in Early Childhood. Dordrecht: Springer.

Kals, E., Schumacher, D., and Montada, L. (1999). Emotional affinity toward nature as a motivational basis to protect nature. Environ. Behav. 31, 178-202. doi: $10.1177 / 00139169921972056$

Kellert, S. R., and Wilson, E. O. (eds) (1995). The Biophilia Hypothesis. Washington, DC: Island Press.

Knight, S. (2013). Forest School and Outdoor Learning in the Early Years. London: Sage.

*Kossack, A., and Bogner, F. X. (2012). How does a one-day environmental education programme support individual connectedness with nature? J. Biol. Educ. 46, 180-187. doi: 10.1080/00219266.2011.634016

Leary, M. R., Tipsord, J. M., and Tate, E. B. (2008). "Allo-inclusive identity: incorporating the social and natural worlds into one's sense of self," in Transcending Self-Interest: Psychological Explorations of the Quiet Ego, eds H. A. Wayment and J. J. Bauer (Washington, DC: American Psychological Association), 137-147. doi: 10.1037/11771-013

*Liefländer, A. K., Fröhlich, G., Bogner, F. X., and Schultz, P. W. (2013). Promoting connectedness with nature through environmental education. Environ. Educ. Res. 19, 370-384. doi: 10.1080/13504622.2012.697545

Louv, R. (2008). Last Child in the Woods: Saving Our Children from Nature-Deficit Disorder. Chapel Hill, NC: Algonquin books.

Lumber, R., Richardson, M., and Sheffield, D. (2017). Beyond knowing nature: contact, emotion, compassion, meaning, and beauty are pathways to nature connection. PLoS One 12:e0177186. doi: 10.1371/journal.pone.0177186

Mayer, F. S., and Frantz, C. M. (2004). The connectedness to nature scale: a measure of individuals' feeling in community with nature. J. Environ. Psychol. 24, 503-515. doi: 10.1016/j.jenvp.2004.10.001

McCree, M., Cutting, R., and Sherwin, D. (2018). The Hare and the Tortoise go to Forest School: TAKIng the scenic route to academic attainment via emotional wellbeing outdoors. Early Child Dev. Care 188, 980-996. doi: 10. 1080/03004430.2018.1446430

Miller, J. R. (2006). Restoration, reconciliation, and reconnecting with nature nearby. Biol. Conserv. 127, 356-361. doi: 10.1016/j.biocon.2005.07.021

*Mullenbach, L. E., Andrejewski, R. G., and Mowen, A. J. (2018). Connecting children to nature through residential outdoor environmental education. Environ. Educ. Res. 25, 365-374. doi: 10.1080/13504622.2018.1458215

Müller, M. M., Kals, E., and Pansa, R. (2009). Adolescents' emotional affinity toward nature: a cross- societal study. J. Dev. Process. 4, 59-69.

Munafò, M. R., Nosek, B. A., Bishop, D. V., Button, K. S., Chambers, C. D., Du Sert, N. P., et al. (2017). A manifesto for reproducible science. Nat. Hum. Behav. 1:0021. doi: 10.12688/f1000research.5686.2

Nelder, J. A., and Wedderburn, R. W. (1972). Generalized linear models. J. R. Stat. Soc. Ser. A 135, 370-384.

Nisbet, E. K., and Zelenski, J. M. (2013). The NR-6: a new brief measure of nature relatedness. Front. Psychol. 4:813. doi: 10.3389/fpsyg.2013.00813

Nisbet, E. K., Zelenski, J. M., and Murphy, S. A. (2009). The nature relatedness scale: linking individuals' connection with nature to environmental concern and 14ehaviour. Environ. Behav. 41, 715-740. doi: 10.1177/0013916508318748

Otto, S., and Pensini, P. (2017). Nature-based environmental education of children: environmental knowledge and connectedness to nature, together, are related to ecological behaviour. Glob. Environ. Change 47, 88-94. doi: 10.1016/j. gloenvcha.2017.09.009

Pearl, J. (2009). Simpso's Paradox, Confounding, and Collapsibility in Causality: Models, Reasoning and Inference, 2nd Edn. New York, NY: Cambridge University Press.

RSPB (2015). The Impact of Children's Connection to Nature: A Report for the Royal Society for the Protection of Birds (RSPB). Available online at: https://www.rspb.org.uk/globalassets/downloads/documents/positions/ education/the-impact-of-childrens-connection-to-nature.pdf (accessed March 11, 2019).

*San Jose, A. L., and Nelson, K. E. (2017). Increasing children's positive connection to, orientation toward, and knowledge of nature through nature camp experiences. Int. J. Environ. Sci. Educ. 12, 933-944.

* Schneider, J., and Schaal, S. (2017). Location-based smartphone games in the context of environmental education and education for sustainable development: fostering connectedness to nature with Geogames. Environ. Educ. Res. 24, 1597-1610. doi: 10.1080/13504622.2017.138 3360

Schultz, P. W. (2002). "Inclusion with nature: the psychology of human-nature relations," in Psychology of Sustainable Development, eds P. Schmuck and W. P. Schultz (Boston, MA: Springer), 61-78. doi: 10.1007/978-1-46150995-0_4

*Sellmann, D., and Bogner, F. X. (2013). Effects of a 1-day environmental education intervention on environmental attitudes and connectedness with nature. Eur. J. Psychol. Educ. 28, 1077-1086. doi: 10.1007/s10212-0120155-0

Tam, K. (2013). Concepts and measures related to connection to nature: similarities and differences. J. Environ. Psychol. 34, 64-78. doi: 10.1016/j.jenvp.2013.01.004

Unsworth, S., Palicki, S. K., and Lustig, J. (2016). The impact of mindful meditation in nature on self- nature interconnectedness. Mindfulness 7, 1052-1060. doi: 10.1007/s12671-016-0542-8

van't Veer, A. E., and Giner-Sorolla, R. (2016). Pre-registration in social psychology-a discussion and suggested template. J. Exp. Soc. Psychol. 67, 2-12. doi: 10.1016/j.jesp.2016.03.004

Wells, N. M., and Lekies, K. S. (2006). Nature and the life course: pathways from childhood nature experiences to adult environmentalism. Child. Youth Environ. $16,1-24$.

Wigfield, A., and Eccles, J. S. (2002). "The development of competence beliefs, expectancies for success, and achievement values from childhood through adolescence," in Development of Achievement Motivation, eds A. Wigfield and J. S. Eccles (London: Academic Press), 91-120. doi: 10.1016/b978-0127500539/50006-1

Zelenski, J. M., and Nisbet, E. K. (2014). Happiness and feeling connected: the distinct role of nature relatedness. Environ. Behav. 46, 3-23. doi: 10.1177/ 0013916512451901

Conflict of Interest: The authors declare that the research was conducted in the absence of any commercial or financial relationships that could be construed as a potential conflict of interest.

Copyright (c) 2020 Barrable and Booth. This is an open-access article distributed under the terms of the Creative Commons Attribution License (CC BY). The use, distribution or reproduction in other forums is permitted, provided the original author(s) and the copyright owner(s) are credited and that the original publication in this journal is cited, in accordance with accepted academic practice. No use, distribution or reproduction is permitted which does not comply with these terms. 